\title{
The Significance of Trust to the Adoption of E-Working Practices Within Local Government
}

Hazel Beadle, University of Chichester, Bognor Regis, UK

\begin{abstract}
Drawing upon an in-depth study of one local authority based in the United Kingdom, this article examines the significance of trust to local government workers who are beginning to make increasing use of e-technologies through e-working practices. The article identifies trust to be of particular significance but that the examined context is not supportive of that trust being developed. It notes differences in the perceptions surrounding trust development, that consideration of trust is not just limited to the relationship between management and their workers, and that there is a fear that trust is at risk of abuse. In the face of e-work serving to raise the profile of trust as a significant factor for concern, the associated technologies are suggested to have the potential to offer a solution to some of the issues arising.
\end{abstract}

\section{KEYWORDS}

E-worker, E-working, Trust, Culture, Case study, Local Authority, Local Government

\section{INTRODUCTION}

When considering the increasing use of e-technologies, electronically facilitated technology-based provision, focus tends to be placed on the associated hardware and software. Receiving less attention are the perceptions of those who are called upon to use those resources; the workforce. Since it is the workforce who execute organisational information technology strategies (Iyamu, 2014), and change associated with technology is acknowledged to cause uncertainty (Meier et al., 2013), this is surprising. One effect of this decreased focus is the development of a mythologised environment and a risk of management being based on assumptions (Van den Broek \& Keating, 2011).

This paper is drawn from an unpublished doctoral research study investigating the increasing use of e-working in one local authority organisation based in the United Kingdom (UK). The study's context is significant in that there is little material about worker use of e-technologies within local government in the UK, much less studies in that context which focus on the perceptions of workers.

E-working is a term readily used in practice but which has received limited explanation within the literature. It is, therefore, a term which has contributed to the perpetuation of what Barley (1990) 
terms 'a maze of analytic abstractions'. An analysis of the related literature, undertaken as part of the aforementioned doctoral study identified e-working to be

... a mechanism for executing work tasks utilising technology in the form of electronic media. Since these tasks are so broad ranging, what the work tasks associated with e-working amount to is largely immaterial. Technological media is subject to development. This developmental factor, seen in the literature as having impeded the provision of technology related definitions, is central to the reality of working with technology. Embracement of development contributes to terminological longevity. It also heightens awareness of innovative practice; including ways of culturing and sustaining the relationship between the worker and the technology made available to them. Thus, in brief, e-working is...both a way of being a worker as well as a way, or mechanism, for carrying out the work task.

In this paper it is in relation to trust, noted to be a 'complex, multi-faceted, and context dependant concept' (Corritore et al., 2012), that the e-working focus is examined. Making use of the aforementioned conceptualisation of e-working, the focus of this paper is how trust is perceived to be relevant to local government workers who are making increasing use of e-technologies.

\section{LITERATURE REVIEW}

The literature is considered under three headings. After this brief introduction where the trust term is explored, attention turns to the context of the study; local government. This is followed by two sections examining factors significant to the perception of trust in the e-environment; the potential for liberation arising from use of, and communication in the presence of, e-technologies.

Trust is a term which is regard to be 'intuitively understood' despite being context specific (Mouzas et al., 2007). Indeed, there is suggestion that 'the domain of trust is rarely specified and its conceptual dimensions are used with imprecision and ambiguity' as a consequence of the concept being associated with inherently personalised factors such as beliefs and expectations (Mouzas et al., 2007). In the context of this paper, the issue of trust is contained to an organisational context; deemed to be a popular area of the trust debate (Vidotto et al., 2008; Kramer and Lewicki, 2010).

There are two strands of organisation-related trust debate apparent within the literature. Firstly, there is the debate relating to the repairing of trust, specifically where the perception of trust has been compromised and, secondly, there is the debate relating to how an existing level of trust can be sustained (Kramer and Lewicki, 2010; Caldwell et al., 2008). Both hinge on the perception that the presence of trust is inherently positive and something that is worth striving to achieve (Goel et al., 2005). Operationally the effect of trust is related to the links which can be drawn between how the worker feels, for example how trusted they consider themselves to be, and how they behave - the reaction to the perception of trust (Perrone et al., 2003; Dynes et al., 2013). Inevitably context plays a role in that perception and it is the context of the local government organisation, which is central to this study.

\section{The Local Government Context}

Although there is a sizable body of literature about local government per se, the volume of material about the use of e-technologies in local government in the UK, much less the implications for the respective workforce of increasing the use of those technologies, is limited. This is surprising because the use of technology in local government more broadly has received significant governmental focus. Writing a decade ago King \& Cotterill (2007), for example, emphasised how transformation of local authorities had taken a central role in the UK government's political programmes over the preceding two decades, with technology playing a key role. 
Beyond the United Kingdom, it is seen that whilst some technology-related local public administration studies have been undertaken within Europe, particularly Italy (e.g. Della Rocca, 2000; Arduini et al., 2010), the Scandinavian countries (e.g. Baldersheim \& Øgård, 2008; Van Veenstra et al., 2012) and, noting Reinsalu's (2006) work, within and related to the State of Estonia; the greatest breadth of research has taken place within the United States of America (e.g. McNeal et al., 2008; Wohlers, 2009). However, even this material demonstrates little focus on the experience of the worker and thus a gap in that literature is evident.

With some blurring in the use of the 'technology' and 'e-technology' terms evident, potentially reflecting how contextualised application of technology becomes developed and embedded into operational practice, as well as the role played by the internet (Ho, 2007), the literature identifies the 'transformational' potential of using e-technologies in the local government setting. Writing beyond the focal UK setting Ho and Ho (2006) identify, for example, technology to be used for the improving, or transforming, of services which the public receive. This amounts to far more than the simple use of personal computers for handling routine business tasks (Ho, 2007).

Inevitably the extent to which transformation has occurred is influenced by the initial reticence to adopt technology (Asgarkhani, 2005). It is this reticence which contributed to perceptions of local government languishing behind its private sector comparators. In the early 1980s King (1982) suggested that whilst sophisticated application of information technology is plausible 'there is no $a$ priori reason to expect that they will come to pass in the near future'. In other words, highlighting that change could happen but that it was unlikely to occur in the short-term. In part this appeared to be the consequence of a 'sitting out change' approach in order to make a more informed assessment once those e-technologies had been used elsewhere. This is not an untypical approach for UK local authorities to take.

Two decades later some writers (e.g. Worthington \& Dollery, 2000; Wohlers, 2009) highlighted there to be increasing adoption of e-technologies in the local government context, with the change in approach credited to technological progression during the intervening time period. Local government was suggested to have awoken to a need 'to stay current with ever-changing technological applications' (Norris \& Jae Moon, 2005), with factors such as the central government drive to 'achieve $100 \%$ electronic service delivery capability' (Paris, 2005), reduced public funding and raised efficiency targets all having a significant influence. Indeed, the context of the examined case study reflected the factors highlighted through the literature and were directly mentioned in the corporate explanation for the increased focus on e-working. Also noted was that the literature places limited emphasis on whether use of e-technologies is the best means for achieving operational efficiencies within local government, suggesting that the adoption of e-technologies within local government is as a one-way route.

Some of the initial reticence associated with implementing technological solutions in local government appears to have been a consequence of what Della Rocca (2000) terms the 'public administration paradox'. The paradox is identified in the mismatch between a belief in the continuous value of historical operational practices, and the emphasis placed on meeting contemporary service requirements. Indeed, this mismatch might well account for operational processes having been purposefully targeted; for example, through the central government driven reform agenda (Worthington \& Dollery, 2000) wherein emphasis was placed on significant organisational change being brought into play as opposed to a simple 'repackaging' of the existing product.

Worker responsiveness, however, is influenced by the context in which their work is conducted (Stachova et al., 2015); the organisation's culture. Whilst the literature provides a wealth of material in relation to organisational culture generally, specific focus on culture within local authorities is limited. Indeed Sandford (2006) highlights that "almost nowhere in local government or scrutiny literature is there any focused discussion or analysis of what local government 'culture' actually is... No literature exists on this subject". It can be questioned whether this is the consequence of, as Orr \& Vince (2009) highlight, there being no such thing as a single local government culture or whether 
it is the result of that culture being a 'fluid 'blooming buzzing confusion' of traditions, beliefs and assumptions' (Sandford, 2006).

In contrast to the limited detail provided about the nature of the culture within the local government organisation, the literature (e.g. Hayes \& Macleod, 2008; Silver \& Clark, 2013) flags up local authorities as having an increasing interest in the culture experienced within the society that they serve. Indeed, this 'outward looking' focus serves to emphasise the absence of attention on the internal, and therefore the worker-orientated, implications of the local authority culture; the context within which any perception of trust may flourish or flounder. It is within this context which the local government worker encounters e-technologies.

\section{Liberation Through Use}

Leadbeater's (2003) work highlights how, as a consequence of the application of e-technologies, information and responsibilities have generally moved to 'front line employees'. Identified is an underpinning focus on technology facilitating individuals to take responsibility for their work and, if responsibility equates to finding a mechanism for fulfilling requirements, then it is difficult to refute that there is potential for local government workers to feel 'liberated' through their use of e-technologies. This perception is argued to be pivotal to a perception of trust (Perrone et al., 2003). However, there are other factors, consequent to the presence of e-technologies, which also impact upon the working environment and, therefore, any perception of liberation.

One of these factors is the issue of flexible specialisation. Leadbeater (2002) alludes to this when writing about the 'mix and match' potential of technology. Underpinning the flexible approach is a moulding of the use of e-technologies according to prevailing organisational circumstances (Dawson, 2003; Garman, 2005); an approach which is allied to the moulding of the use of technology more broadly (Bouzaabia et al., 2016). Thus, if there is a desire to effect worker liberation through the use of e-technology, then this desire might be accommodated.

It is acknowledged that management operates through people as opposed to functioning as disembodied practice (Leadbeater, 2003; Fleming et al., 2004). In exercising that management role there is potential to incorporate limiting measures, whether or not this potential is consciously recognised (Rosen \& Baroudi, 1992; Sewell \& Wilkinson, 1992). Thus it might well be through a process of 'deemphasizing managerial control' (Fuller \& Smith, 1991) that individuals gain a perception of being empowered, or trusted, to undertake their work role.

However, despite the potential to perceive trust there are factors which risk undermining that perception. One of these factors is the potential for hidden constraint and the panoptican-like systems which receive attention in the Foucault-related literature. Foucault's writing about panoptican-like systems of control and domination relate to the risk of observation and the impact that that risk has on compliance (Foucault, 1977). There is suggestion that an omnipresent perspective facilitates fairness on the grounds that everyone can be observed (Townley, 1993; Felstead et al., 2005), with the risk of observation positively influencing the likelihood of required behaviours being exhibited and, as a consequence, reducing the need for corrective action (Sewell \& Wilkinson, 1992). A similar theme is echoed in the work of other writers (e.g. Warner \& Witzel, 2004; Valsecchi, 2006) and is one which inevitably has an impact upon individual perceptions of self-determination (Sewell \& Barker, 2006).

With this risk hanging over the worker, it can be questioned whether the technologically-assigned (self) management role largely amounts to managing feelings of uncertainty. Leadbeater (1999) highlights that those using e-technologies are 'living on their wits', enigmatically capturing the need to maintain confidence, competence and motivational self-belief in a working environment where the nuancing effects of e-technologies are accelerating.

Thus, whilst the use of technology has the potential to prove liberating, or empowering, what that perception amounts to may not be immediately comparable with other uses of the term. It can, for instance, be questioned whether trust is a composite feature, or simply an illusion. 


\section{Communication}

One area where e-technologies play a key role is in facilitating communication within the organisation, acknowledging that communication is more than the simple exchange of words (Dawson, 2003; Fairhurst \& Putnam, 2004). Indeed, communication is acknowledged to be comprised of four domains; business, management, corporate and organisational (Kalla, 2005); with, for the purpose of this paper, focus placed on an amalgam of the latter three elements since these robustly embrace the within-organisation perspective. Despite acknowledgement of the influence of the management role in system adoption (Ho and Ho, 2006), somewhat ironically the significance of internal communication is argued to have come to the fore as a consequence of ".... a drastic reduction of trust employees have in [that] management..." the consequence of detachment fuelled by the use of e-technologies (Tkalac Verčič et al., 2012).

Barley (1990) highlights that where e-technologies are adopted within organisations, that a piecemeal approach is often used; an approach which allows learning, for example in relation to communications processes, to occur (Dawson, 2003). One of those areas of learning relates to the satisfying of socialisation needs through electronic means (Layder, 2006; Liu et al., 2013). Socialisation plays a role in ensuring compliance through the provision of a 'framework' for behaviour (McBride, 1986; Stanworth \& Stanworth, 1991), offering a parallel to the aforementioned panoptical approach.

The literature is silent on how workers handle e-socialisation capabilities where the organisational preference lacks clarity. The way ideas are conveyed inevitably influences the understanding that arises (Leonardi \& Jackson, 2004; Hogler et al., 2008). Organisational procedural documentation provides an example, with its tendency towards a 'pigeonholing' approach in assuming that all workers can be satisfactorily handled the same way; that trust, for example, is consistently perceived by workers exposed to the same operating processes. Whilst this approach amounts to 'gross categorisation' (Alvesson, 2000; Fairhurst \& Putnam, 2004), the removal of procedural direction can cause anxiety.

Also contributing to the communications approach is the structure of the organisation. The task of briefing workers is influenced by the way in which the organisation is constructed (Ogbonna \& Harris, 2005), with that structure influenced, in turn, by the organisation's culture. The contribution to the briefing process of organisational size is also acknowledged, with Marks \& Huzzard (2010) proposing that one of the benefits of the pursuit of an optimal organisational size is the opportunity to sift out workers failing to embrace the changes associated with introducing e-technologies.

Recent writing (e.g. Eikeland, 2015) suggests that there is a need for greater understanding of the trust concept. The volume of literature about the use of e-technologies in local government in the UK, much less the implications for the workforce of the increasing the use of e-technologies, has been identified to be limited. This study contributes towards a filling of the gap in understanding relating to these issues. Specifically, this paper examines the significance of trust to local government workers who are beginning to make increasing use of e-working practices.

\section{METHOD}

The study made use of a single local authority case study. The selected case was a local authority which at the point of examination had only recently decided to actively embrace e-working practices. Qualitative data was gathered through the use of single semi-structured interviews which explored understanding of the e-working term; the expectations and understanding associated with changing working practices; and the accommodation of worker and worker body needs. These themes were derived from an analysis of the literature which had resulted in the devising of the aforementioned definition of e-working.

The underpinning trajectory was to elicit an understanding of the perspectives held at the point when, within the organisation, increasing use was being made of e-working. Each of the 21 interviews lasted up to one hour and took place over a period of 6 months commencing in 2012. 
The e-working participants included those who had links to the trade union as well as those who held management roles. Whilst all workers were invited to participate, a diversity of participants was sought mindful of Currie \& Brown's (2003) identification of the value of case studies 'incorporat[ing] plurivocal understandings' and, furthermore, realising that change management involves workers at all levels (Pettigrew, 1985).

The data was gathered, transcribed and analysed by the writer in her role as a supervised part time $\mathrm{PhD}$ student, with a process of thematic content analysis used to draw meaning from the data collected. Smaller categories were subsequently merged to provide larger themed units, as illustrated in the following section.

\section{FINDINGS AND DISCUSSION}

Five themed sections, each derived from the data and with a trust-associated undercurrent, are presented. In turn the themes relate to the changing of the organisational culture; generation of enthusiasm; the potential for monitoring; the rise of e-socialisation and empowerment.

\section{Changing the Organisational Culture}

Almost without exception participants suggested the organisation's culture needed to change in order that it might benefit from the potential of e-technologies, as applied through increasing use of e-working. This was not regarded as a challenge that would be easy to fulfil but one, in the words of Participant 5, an e-worker in a technical department, where "...the positives outweigh the negatives so you are going to have to live with a few issues..."

E-working, and in particular the flexibility of working practices which the associated technology can facilitate, was identified to require the organisation to embrace mechanisms of work which, in the words of Participant 3, it had 'shied away from in the past'. That this risked causing discomfort was acknowledged. Furthermore, there was a suggested mismatch of expectations between those who had worked in local government for any length of time and recently recruited workers who were suggested to be more familiar with the impact of e-technologies on the worker role. This should, perhaps, not be surprising for, as Participant 11 highlighted, "a judgement is made about the required skill set at the time of recruitment..."

Trust was, akin to the perception portrayed by Goel et al. (2005), regarded as a positive feature. However, there was invariably caution attached. Participants, including those without managerial roles as illustrated by the following example, questioned whether trust was being abused where individuals were facilitated to carry out their duties outside of their traditional working environment:

Sometimes I'll be wondering what my colleagues are doing. I'll be wondering whether they are working or whether they are doing something at home. I don't know. It is not something for me to worry about but I wonder what they're doing. [Participant 4].

Asked how organisational trust was being generated, responses took one of two routes. The majority perspective suggested that trust was something which would inherently arise albeit this would take time and entail some turnover within the existing cohort of workers. Here there was an identified absence of urgency and little desire to actively seize the potential highlighted in the literature (e.g. Marks \& Huzzard, 2010) to actively sift out workers who failed to respond to the potential of technological change. Participant 11 described this in terms of

...going in the right direction. They want this to be a significant change, a cultural change for this organisation. It is going to take time because that's how the mechanisms of local government work. 
The second perspective suggested that trust could be cultured through 'stock' resolutions such as being instructed to think differently; 'to trust'. The organisation's Human Resources Department, for example, had identified some online training and, consequent to engaging with this provision, argued that changed behaviours would automatically result.

\section{Generating Enthusiasm}

The rigidity with which the management role had been traditionally fulfilled within the organisation, with that rigidity impacting upon the ability to exhibit trust, was regularly raised by participants. Management practices largely amounted to adhering to written procedures which precluded variation or uncertainty. Three participants, all managers, proposed that a 'Dickensian label' would serve as a useful descriptor for the organisation's historical style of management.

How this historical style contrasted with requirements in the presence of e-technologies was illustrated by Participant 5, who identified that their manager had demonstrated the required approach:

[They] don't have to be on my back all the time. [They] don't need to know what I'm doing all the time. [They] don't need to check the results of my work or anything like that. They just need to be [available] to support me... and to ensure that my focus or the overview of where I am going is in the right direction.

Participant 2, one of the managers who were spoken about as providing an example of the required approach, highlighted that a further change was evident in the blurring of the distinction between working and non-working lives. In doing so he acknowledged that the associated decrease in clarity had the potential to cause discomfort; in part because the work role risked having an unfamiliar impact upon those surrounding the individual.

Participant 10, a manager in an administrative department, highlighted that the decreased clarity also impacted upon managerial expectations. He provided an example which highlighted the need to acknowledge limitations in worker availability despite the increased flexibility offered through e-working:

If they say 'I can only work till 3 but I am e-working remotely' then you don't expect to phone them at 4 and say 'Well I know you technically finished at 3 but I still want to contact you, I still want your help' [Participant 10].

Some enthusiasm was generated by managers being facilitated through the use of e-technologies to become more immersed in their professional (as opposed to managerial) discipline. It was the removal of the day-to-day emphasis on the controlling stance, the consequence of needing to trust workers to satisfactorily complete their roles, together with how this contrasted with historical working arrangements, which was suggested to be significant.

\section{The Potential for Monitoring}

The potential for technology to be used to monitor the workforce was acknowledged. Participant 10 described monitoring to be 'a side effect of technology's presence'; a view aligning with the literature (e.g. Dawson, 1988).

However, a number of those in managerial roles indicated that they believed a lack of obtrusiveness equated to worker ignorance of the monitoring potential. Some managers gained pleasure from this perception. Indeed, one manager recounted joking with a peer about the extent of their monitoring capabilities.

It was not clear why some managers perceived there to be a lack of an awareness of the monitoring potential. However some managers did indicate that they found the presence of monitoring capabilities 
to be unsettling and that they sought to manage the associated anxiety. Participant 9, a manager in an administrative department, suggested that by failing to identify an awareness of monitoring that it 'save[d] putting ideas into people's heads'.

If monitoring is perceived to undermine trust, and trust is pivotal to effective use of e-technologies through e-working, then an attempt to conceal the potential to engage in monitoring activities might be argued to be appropriate. Furthermore, if concealment is not achievable then the practice of justifying monitoring activities could prove to be a substitute position. Whilst both perspectives were exhibited in the data, a number of participants mentioned organisational policies and the right to 'observe' workers which was embraced by that documentation. As highlighted by Participant 1 , "It is always there. There is a communications policy so it is always there with regard to internet access and so on being monitored". There was also mention of monitoring being used to check on the safety of workers. In relation to use of Global Positioning System (GPS) tracking Participant 3, for example, suggested this was supportive in that it enabled 'an alert in case anything happens'. However this supportive perspective was off-set by comments regarding the ability to use GPS solely for the purpose of checking whether work was being actively undertaken.

Thus a tension was identified between the potential for e-facilitated monitoring and the uses to which that monitoring capability can be put. If all sides to the employment relationship are operating within a framework of trust then, as Participant 2 explained, "staff shouldn't care about, shouldn't even think about whether they are being monitored". However, in the studied local authority, this framework of trust appeared to be absent and thus the impact of the potential to monitor was regarded to be significant.

\section{The Rise of E-Socialisation}

Participants used a variety of terms when discussing communications, potentially reflective of the domains identified within the literature (Kalla, 2005). However, 'being in touch' and 'social' were the most popular. Despite gaps in understanding how e-technologies functioned, there was indication that socialisation had the effect of generating feelings of inclusion and that the technology associated with e-working might facilitate new ways of fulfilling work-related social needs; needs which were highlighted to be of particular significance if working remotely.

However significantly influencing participant embracement of the e-facilitated approaches was the effect resulting from a number of operational mechanisms converging. Policy provision was one influence, with an expectation that 'protocol policies' would be adopted for e-socialisation being regularly raised. It was suggested that the perception of needing such a framework, as well as the time period associated with policy generation, undermined the potential to generate trust. One of the difficulties appeared to be an inability to effectively communicate changed approaches. As Participant 21 highlighted:

We have got something called Yammer, if you have heard of that but there was no launch of it or any instruction that you could use it to communicate between staff. I got an invite from [name] and thought 'why has she invited me to this? What is it? I clicked on it and accepted and looked at it. It was obviously a way to communicate but there was no distinction as to which tool the organisation wants us to be using for what.

There were participants who suggested that they would only use the e-socialisation provision with which they felt comfortable and that in the absence of a trust culture, that this comfort was limited. Facebook and Twitter were named as examples of platforms which were increasingly used within the organisation but which were regarded to have generated discomfort amongst the workforce. Yammer was, as the following quote from Participant 21 illustrates, generating a similar effect: 
Some people are just posting on this Yammer stuff the crap that they would put on Facebook socially, so what is the barrier? It makes me sound really up tight and it would be nice to have something that would be relaxed without worrying that the Chief Exec might be reading your comments, but people are putting some weird things on.

Whilst, therefore, there was evidence of efforts to respond to worker socialisation needs, the effectiveness of using e-technologies for that purpose appeared to be being hindered by perceptions of trust and the extent to which the new ways of working differed from the familiarity offered by the historical processes. Thus the perception of e-socialisation in the context of the studied environment was identified as being one of limitations and the result was a leaning towards perpetuation of the status quo.

\section{Empowerment}

The literature suggests that whether an individual perceives they are, or are not, empowered, depends upon both their control over the work location (Feldman \& Gainey, 1997; Edwards \& Collinson, 2002) and their perception of task ownership (Klein, 1989; Rubery \& Grimshaw, 2001). This latter element includes the deemphasising of managerial control (Fuller \& Smith, 1991). Thus the existence of empowerment is determined by the individual worker.

The study identified it was those holding management roles who made particular use of the 'empower' term. However, this did not mean that empowerment was part of the reality for their staff. Indeed Participant 8 was seen to acknowledge this optimistic focus in their use of the "I would hope that they're more empowered" phraseology.

Trust has already been highlighted to have not historically been a feature of the local authority working environment. Generation of trust was not indicated to require the removal of management per se, but efforts to generate trust were highlighted to be associated with managers adopting more facilitative (empowering) approaches. Despite this need being identified, several participants mentioned managers requiring sight of completed task lists when, using the capabilities of e-technology, work was undertaken out of their sight. However Participant 2, an e-worker and manager, highlighted how one of his own e-workers had provided without request a detailed listing of the work undertaken. He recalled having berated the individual for feeling they needed to prove they were working but then acknowledged that this was an approach that he had also used: "Because in my mind I am thinking I've got to let that person know I'm working”. Suggestion that proof is required indicates the absence of trust.

Empowerment might arise from an absence of formal instruction, allowing the individual to feel they are able to make their own decisions regarding the execution of their role. This might, therefore, be perceived as being the benchmark which workers may be desirous of achieving. However such an approach was repeatedly described, by those identifying themselves as having the potential to undertake e-working, as being 'let loose'. The inference was that far from being empowered to make decisions, these individuals felt unsupported.

Also inducing anxiety was the risk of the level of fear being sustained. It would be an incorrect reflection of the data to suggest that there were no managers who were identified as exhibiting trust, but certainly there was evidence to indicate that managers who were desirous of being trusted were encountering difficulties. Participant 2, a manager, highlighted:

It's the culture of the organisation. It's about trust. It is exactly about that trust. They didn't believe that I trusted them if that makes sense because they've only ever known the traditional style of management and things like that. [The trust associated with e-working] was a completely different mindset to get across.

In summary, the potential surrounding the adoption of e-working practices to highlight the absence of trust in local government workers to fulfil their job roles was noted, despite general consensus that 
the presence of trust was both positive and desirable. There was an absence of consensus with regard to how that trust might be generated in the presence of increasing use of e-working, with the influence of an historically favoured regulated approach playing a significant role. Indeed e-technologies, for example in the capacity for monitoring workers, were identified as having the potential to be used in such a manner that there was active undermining of any perception of trust.

The prospect of trusting workers to carry out their duties as e-workers, minded that this encapsulates the way of being a worker (one part of the aforementioned e-working conceptualisation) was acknowledged to offer benefits to those in managerial roles as well as those who reported to those managers. Those in managerial roles were, for example, highlighted in the presence of increasing use of e-working practices as having the opportunity to place increased focus on their primary professional discipline. However, despite the desire expressed by some managers to benefit from this revised position, workers appeared to pick up on a more cautious managerial perspective. Thus, despite evidence of small pockets of changed operating processes, the potential to generate a sizable body of trust within the organisation was negated.

\section{CONCLUSION}

The focus of this paper has been to examine the significance of trust to local government workers who are beginning to make increasing use of e-working practices. That the study has identified trust to be of particular significance is not surprising in the light of the focus placed on the perception within the literature more broadly (e.g. Vidotto et al., 2008; Kramer and Lewicki, 2010). However this paper offers value by identifying this significance through a study conducted in a local government context, a largely neglected area of focus, where trust was identified to be desired but where the context was not supportive of that trust being developed. Differences in the perceptions surrounding how trust might be developed appear to be problematic. Since trust has been identified to be perceived as being central to the increasing use of e-working, actions suggesting there to be an absence of urgency with regard to the development of that trust inherently have a stalling impact. Of influence here is the fear that trust, if developed, might be abused. From an operational perspective, the study has noted the need to focus on intra-organisational cultural change, the subject of current research activity.

Acknowledging, as Sandford (2006) highlights, the 'fluid 'blooming buzzing confusion' of traditions, beliefs and assumptions' which constitute the local authority culture, the study has highlighted that the trust is not limited to the relationship between management and their workers, but also with workers trusting their peers. Thus this paper contributes to unpacking a little further, specifically within the context of the local government organisation, the magnitude of and factors requiring examination in the effecting of cultural change.

Finally, whilst e-working is identified as serving to raise the profile of trust as a significant factor for concern, the associated technologies are identified to offer a solution to some of the issues arising. Technology's facilitation of socialisation is identified, for example, to have the capacity to generate perceptions of inclusion and that inclusion has a positive and perpetuating effect, for example through its influence on a worker's self-regulation of behaviour.

Inevitably this research has limitations. First, the study was exploratory and whilst it purposefully sought the perceptions of the participants, those perceptions are subject to change. Whilst participants were self-nominating and all of the local authority's workers were invited to participate, it is inevitable that the viewpoints held by some employees were not captured. The effect on the findings of a failure to capture these perspectives can only be surmised. The study explored one local authority organisation, with the choice of organisation influenced by that organisation being in the process of increasing its use of e-working processes. Since other local authority organisations in the UK have already embraced e-working arrangements, the extent to which learning from the study can be used at a practical level in other organisations is limited. However, the relevance of trust where e-working has become embedded is an avenue for future research activity. 


\section{REFERENCES}

Alvesson, M., \& Karreman, D. (2000). Varieties of discourse: On the study of organizations through discourse analysis. Human Relations, 53(9), 1125-1149. doi:10.1177/0018726700539002

Arduini, D., Belotti, F., Dennis, M., Giungato, G., \& Zanfei, A. (2010). Technology adoption and innovation in public services - the case of e-government in Italy. Information Economics and Policy, 22(3), $257-275$. doi:10.1016/j.infoecopol.2009.12.007

Asgarkhani, M. (2005). Digital government and its effectiveness in public management reform. Public Management Review, 7(3), 465-487. doi:10.1080/14719030500181227

Baldersheim, H., \& Øgård, M. (2008). Innovation in e-government: Analysis of municipal web pages in the Nordic countries. Democracy in the Information Age, 13(3/4), 125-137.

Barley, S. (1990). The Alignment of Technology and Structure through Roles and Networks. Administrative Science Quarterly, 35(1), 61-103. doi:10.2307/2393551 PMID:10106582

Bouzaabia, O., Bouzaabia, R., \& Capatina, A. (2016). Determinants of internet use by senior generation: A cross cultural study. International Journal of Technology and Human Behaviour, 12(1).

Caldwell, C., Hayes, L., Bernal, P., \& Karri, R. (2008). Ethical Stewardship - Implications for Leadership and Trust. Journal of Business Ethics, 78(1), 153-164. doi:10.1007/s10551-006-9320-1

Corritore, C., Wiedenbeck, S., Kracher, B., \& Marble, R. (2012). Online trust and health information websites. International Journal of Technology and Human Behaviour, 8(4), 92-115. doi:10.4018/jthi.2012100106

Currie, G., \& Brown, A. (2003). A narratological approach to understanding processes of organizing in a UK hospital. Human Relations, 56(5), 563-586. doi:10.1177/0018726703056005003

Dawson, P. (1988). Information Technology and the Control Function of Supervision. In D. Knights \& H. Willmott (Eds.), New Technology and the Labour Process (pp. 118-142). Basingstoke: Macmillan. doi:10.1007/978-1349-19242-7_6

Dawson, P. (2003). Understanding Organizational Change: The Contemporary Experience of People at Work. London: Sage.

Della Rocca, G. (2000). The public administration paradox: An organisation with a low degree of institutionalisation. Scandinavian Journal of Management, 16(4), 375-389. doi:10.1016/S0956-5221(00)00013-0

Dynes, M., Hadley, C., Stephenson, R., \& Sibley, L. (2013). Measuring trust among frontline health workers in rural Ethiopia. Human Organization, 72(3), 230-241. doi:10.17730/humo.72.3.y2kk32w73442w6q1

Edwards, P., \& Collinson, M. (2002). Empowerment and managerial labour strategies: Pragmatism regained. Work and Occupations, 29(3), 272-299. doi:10.1177/0730888402029003002

Eikeland, T. (2015). Emergent trust and work life relationships: How to approach the relational moment of trust. Nordic Journal of Working Life Studies, 5(3), 59-77. doi:10.19154/njwls.v5i3.4807

Fairhurst, G., \& Putnam, L. (2004). Organizations as discursive constructions. Communication Theory, 14(1), 5-26. doi:10.1111/j.1468-2885.2004.tb00301.x

Feldman, D., \& Gainey, T. (1997). Patterns of telecommuting and their consequences: Framing the research agenda. Human Resource Management Review, 7(4), 369-388. doi:10.1016/S1053-4822(97)90025-5

Felstead, A., Jewson, N., \& Walters, S. (2005). Changing places of work. Basingstoke: Palgrave Macmillan.

Fleming, P., Harley, B., \& Sewell, G. (2004). A little knowledge is a dangerous thing: Getting below the surface of the growth of 'knowledge work' in Australia. Work, Employment and Society, 18(4), 725-747. doi:10.1177/0950017004047951

Foucault, M. (1977). Discipline and Punish: The birth of the Prison. London: Penguin.

Fuller, L., \& Smith, V. (1991). Consumers’ Reports: Management by Customers in a Changing Economy. Work, Employment and Society, 5(1). doi:10.1177/0950017091005001002 
Garman, A. (2005). Review of Understanding Organizational Change: The Contemporary Experience of People at Work. Personnel Psychology, 58(2), 537-540.

Goel, S., Bell, G., \& Pierce, J. (2005). The perils of Pollyanna: Development of the Over-Trust Construct. Journal of Business Ethics, 58(1), 203-218. doi:10.1007/s10551-005-1415-6

Hayes, D., \& Macleod, N. (2008). Putting down routes: An examination of local government cultural policy shaping the development of heritage trails. Managing Leisure, 13(2), 57-73. doi:10.1080/13606710801933420

Ho, K. (2007). The e-Government development, IT strategies and portals of Hong Kong SAR Government. International Journal of Cases on Electronic Commerce, 3(2), 53-74. doi:10.4018/jcec.2007040105

Ho, S., \& Ho, K. (2006). Success of Electronic Government Information Portal. Journal of E-Government, 3(2), 53-74. doi:10.1300/J399v03n02_04

Hogler, R., Gross, M., Hartman, J., \& Cunliffe, A. (2008). Meaning in Organizational Communication: Why Metaphor is the Cake, not the Icing. Management Communication Quarterly, 21(3), 393-412. doi:10.1177/0893318907309929

Iyamu, T. (2014). The interplay between human and structure in IT strategy. International Journal of Technology and Human Behaviour, 10(1), 83-100. doi:10.4018/ijthi.2014010106

Kalla, H. (2005). Integrated internal communications: A multidisciplinary perspective. Corporate Communications, 10(4), 302-314. doi:10.1108/13563280510630106

King, J. (1982). Local government use of information technology: The next decade. Public Administration Review, 42(1), 25-36. doi:10.2307/976089

King, S., \& Cotterill, S. (2007). Transformational government? The role of information technology in delivering citizen-centric local public services. Local Government Studies, 33(3), 333-354. doi:10.1080/03003930701289430

Klein, J. (1989). The Human Costs of Manufacturing Reform. Harvard Business Review, 67(2), 60-66.

Kramer, R., \& Lewicki, R. (2010). Repairing and enhancing trust: Approaches to reducing organisational trust deficits. The Academy of Management Annals, 4(1), 245-277. doi:10.1080/19416520.2010.487403

Layder, D. (2006). Understanding social theory (2nd ed.). London: Sage. doi:10.4135/9781446279052

Leadbeater, C. (1999). Living on thin air. London: Penguin.

Leadbeater, C. (2002). Up the down escalator. London: Penguin.

Leadbeater, C. (2003). Who will own the knowledge economy? The Political Quarterly, 69(4), 375-385. doi:10.1111/1467-923X.00173

Leonardi, P., \& Jackson, M. (2004). Technological determinism and discursive closure in organizational mergers. Journal of Organizational Change Management, 17(6), 615-631. doi:10.1108/09534810410564587

Liu, F., Lo, H., Su, C., Lou, D., \& Lee, W. (2013). High performance reversible data hiding for mobile applications and human interaction. International Journal of Technology and Human Behaviour, 9(4), 41-57. doi:10.4018/ ijthi.2013100103

Marks, A., \& Huzzard, T. (2010). Employability and the ICT worker: A study of employees in Scottish small businesses. New Technology, Work and Employment, 25(2), 167-171. doi:10.1111/j.1468-005X.2010.00246.x

McBride, T. (1986). White-collar Proletariat. Journal of Social History, 19(4), 727-728. doi:10.1353/jsh/19.4.727

McNeal, R., Hale, K., \& Dotterweich, L. (2008). Citizen-Government Interaction and the Internet: Expectations and Accomplishments in Contact, Quality and Trust. Journal of Information Technology \& Politics, 5(2), 213-229. doi:10.1080/19331680802298298

Meier, R., Ben, E., \& Schuppan, T. (2013). ICT-enabled public sector organisational transformation: Factors constituting resistance to change. The International Journal of Government and Democracy in the Information Age, 18(4), 315-329. 
Mouzas, S., Henneberg, S., \& Naude, P. (2007). Trust and reliance in business relationships. European Journal of Marketing, 41(9/10), 1016-1032. doi:10.1108/03090560710773327

Norris, D., \& Jae Moon, M. (2005). Advancing e-Government at Grassroots: Tortoise or Hare? Public Administration Review, 65(1), 64-75. doi:10.1111/j.1540-6210.2005.00431.x

Ogbonna, E., \& Harris, L. (2005). The adoption and use of information technology: A longitudinal study of a mature family firm. New Technology, Work and Employment, 20(1), 2-18. doi:10.1111/j.1468-005X.2005.00140.x

Orr, K., \& Vince, R. (2009). Traditions of local government. Public Administration, 87(3), 655-677. doi:10.1111/ j.1467-9299.2009.01770.x

Paris, M. (2005). Local e-Government and Devolution: Electronic Service Delivery in Northern Ireland. Local Government Studies, 31(3), 307-319. doi:10.1080/03003930500095137

Perrone, V., Zaheer, A., \& McEvily, B. (2003). Free to be trusted? Organizational constraints on trust in boundary spanners. Organization Science, 14(4), 422-439. doi:10.1287/orsc.14.4.422.17487

Pettigrew, A. (1985). The Awakening Giant: Continuity and Change in ICI. Oxford: Blackwell.

Reinsalu, K. (2006). Is Estonian local e-government responsive to citizens' needs? The case study of Tartu. Information Polity, 11(3-4), 255-272.

Rosen, M., \& Baroudi, J. (1992). Computer-based Technology and The Emergence of New Forms of Managerial Control. In A. Sturdy, D. Knights, \& H. Willmott (Eds.), Skill and Consent: Contemporary Studies in the Labour Process (pp. 213-234). London: Routledge.

Rubery, J., \& Grimshaw, D. (2001). ICTs and employment: The problem of job quality. International Labour Review, 140(2), 165-192. doi:10.1111/j.1564-913X.2001.tb00219.x

Sandford, M. (2006). Westminster Executive meets local government 'culture': Overview and scrutiny in three English county councils. Environment and Planning. C, Government \& Policy, 24(6), 929-946. doi:10.1068/c0442

Sewell, G., \& Barker, J. (2006). Coercion versus care: Using irony to make sense of organizational surveillance. Academy of Management Review, 31(4), 934-961. doi:10.5465/AMR.2006.22527466

Sewell, G., \& Wilkinson, B. (1992). Someone to watch over me - Surveillance, discipline and just-in-time labor process. Sociology, 26(2), 271-289. doi:10.1177/0038038592026002009

Silver, D., \& Clark, T. (2013). Buzz as an urban resource. Canadian Journal of Sociology, 38(1), 1-31.

Stachova, K., Stacho, Z., \& Bartakova, G. (2015). Influencing organisational culture by means of employee remuneration. Business: Theory and Practice, 16(3), 264-270.

Stanworth, J., \& Stanworth, C. (1991). Telework: The human resource implications. London: Institute of Personnel Management.

Tkalac Verčič, A., Verčič, D., \& Sriramesh, K. (2012). Internal communication: Definition, parameters, and the future. Public Relations Review, 38(2), 223-230. doi:10.1016/j.pubrev.2011.12.019

Townley, B. (1993). Performance appraisal and the emergence of management. Journal of Management Studies, 30(2), 221-238. doi:10.1111/j.1467-6486.1993.tb00302.x

Valsecchi, R. (2006). Visible moves and invisible bodies: The case of teleworking in an Italian call centre. New Technology, Work and Employment, 21(2), 123-138. doi:10.1111/j.1468-005X.2006.00168.x

Van den Broek, D., \& Keating, E. (2011). Rights to a process for the masses or select privileges for the few? Telework policy and labour market inequality in Australia. Policy Studies, 32(1), 21-33. doi:10.1080/014428 72.2010 .520559

Van Veenstra, A., Aagesen, G., Janssen, M., \& Krogstie, J. (2012). Infrastructures for public service delivery: Aligning IT governance and architecture in infrastructure development. e-Service Journal, 8(3), 73-97. doi:10.2979/eservicej.8.3.73 
Vidotto, G., Vincentini, M., Argentero, P., \& Bromiley, P. (2008). Assessment of Organisational Trust: Italian adaptation and factoral validity of the Organisational Trust Inventory. Social Indicators Research, 88(3), 563-575. doi:10.1007/s11205-007-9219-y

Warner, M., \& Witzel, M. (2004). Managing in virtual organizations. London: Thomson.

Wohlers, T. (2009). The digital world of local government: A comparative analysis of the United States and Germany. Journal of Information Technology \& Politics, 6(2), 111-126. doi:10.1080/19331680902821593

Worthington, A., \& Dollery, B. (2000). An empirical survey of frontier efficiency measurement techniques in local government. Local Government Studies, 26(2), 23-52. doi:10.1080/03003930008433988

Dr Hazel Beadle is the Leadership and Management specialist in the Institute of Education at the University of Chichester. After 20 years' experience working for a number of local authorities in London and the South of England, Hazel took the opportunity to combine her experience of leading a Local Authority Human Resources Department with teaching. Having gained her PGCE, she spent time teaching in local authorities, the Further Education and Prison sectors and retraining of military personnel leaving the Armed Forces; joining the University of Chichester in 2007. Hazel's PhD looked at e-working within local authorities and her key research interest is to explore the relationship between people and the technology that they use for work or professional related purposes. Hazel has delivered her work at national and international conferences and had her work widely published. 